\title{
The Effect of Injection Molding on Physical Properties of EPDM Rubber
}

\author{
Adam Skrobak $^{1, a}$, Vojtech Senkerik ${ }^{1}$, and Vaclav Janostik ${ }^{1}$ \\ ${ }^{1}$ Tomas Bata Univerzity in Zlin, TGM 5555, 76001 Zlin, Czech Republic
}

\begin{abstract}
The paper a part of research aimed at the alternative of preparing test samples by injection molding. Such an alternative could bring more objective results in the field of testing samples produced in the same technology. The research is aimed at changing the preparation of rubber testing samples - replacing the standard method according to ISO 23529 by the injection method, especially with the use of rubber compounds for injection molding. This article compares and evaluates the selected physical properties (tensile strength and tear strength) of EPDM rubber injection molded samples with samples prepared by the standard method - cutting out of a compression molded plate. The results have shown that using the injection molded samples we will achieve more objective results mainly to determine the tear strength. In the case of tensile strength, the differences are not so significant.
\end{abstract}

\section{Introduction}

When producing rubber products it is necessary to watch and check the mechanical properties whether it be the properties of the processed material, i.e. the rubber compound, or properties of the product itself. This control aims primarily on how the mechanical properties are influenced by the preparation of the rubberprocessing compounds itself, or the change of technological conditions, e.g. the curing time, the curing temperature etc. However, it does not deal with the impact of changing the whole production technology. One of the very productive technologies, which is coming forth, is the production by injection molding. Control of the mechanical properties of rubber products produced by injection molding is mostly performed on testing samples produced in another way according standard ISO 23529 cutting out of a compression molded plate. This distinct way of producing testing samples and final products can result in different mechanical properties.

Injection molding is most effective in continuous production operations. Injection molding differs from compression molding mainly in different remolding of the material. Unlike the usual compression molding or transfer molding, in case of the injection molding the clamping pressure acts earlier than the pressure that transfers the compound into the cavity of a mold, which enables perfect, no flash compression molding, even in case of large and thick-walled products. Another difference is that the compound is heated before the injection molding itself, which allows another significant reduction of the vulcanization period. To achieve untimely scorching of the compound the temperature of the heated compound must not exceed $100{ }^{\circ} \mathrm{C}$. The temperature of the mold, and thus the temperature of the vulcanization, is usually between 150 and $200{ }^{\circ} \mathrm{C}$. These conditions require no heat losses or temperature varying. Rubber compound flow characteristics are affected by viscosity, shear and cure rate. Unlike thermoplastic materials, many rubber compounds are not formulated for injection molding. These compounds do not react well when subjected to shear. Shear is the strain applied to a compound from pressure introduced to the compound during plasticizing in the feed screw, and during the injection process as materials are forced through the injection sprue. Rubber compounds for injection molding differ mainly in the shapes of the vulcanization curves. Appropriate induction period with constant plasticity and high speed of vulcanization are required. This is achieved by a suitable combination of vulcanization accelerators and retarders in the selected vulcanization system. In many compounds that are designed and compounded for injection molding, additional shearing of the material causes lower viscosity and improves the flow characteristics of the material, making it easier to fill difficult part geometries. The heat generated by shearing the material during the injection process can also significantly reduce the required cure time, when compared to other molding processes. [1-3]

Due to the properties of rubber compounds the plastication is carried out in a cylinder with a significant assistance of dissipated energy. The plasticated material is often transferred into an injection cylinder, goes through it and is injected into the cavity of the mold. The injection molding of rubber compounds allows production of thick-walled products in a reduced time and higher quality of the vulcanized rubber. However, it requires more complex processing equipment and, unlike the other technologies, it is less convenient for piece production. [4-5]

\footnotetext{
${ }^{a}$ Corresponding author: skrobak@ft.utb.cz
} 


\section{Experiment}

For this research, a rubber compound on based ethylene propylene diene monomer rubber (EPDM) with sulphur curing agent. The compound appointed for production of automotive parts was chosen. Approximate composition of the compound shown in Table 1.

Table 1. Composition of the compound.

\begin{tabular}{|c|c|}
\hline EPDM rubber & $45 \%$ \\
\hline Filler (carbon black) & $31 \%$ \\
\hline Sulphur curing agent & $13.5 \%$ \\
\hline Plasticizer & $2 \%$ \\
\hline Other additives & $8.5 \%$ \\
\hline
\end{tabular}

This compound shows sufficient scorch time and fluidity, which were verified by a measurement on RPA (Rubber Process Analyzer). The curing temperature $180{ }^{\circ} \mathrm{C}$ was chosen for both methods of prepare test samples (standards method and injection molding method). Three vulcanization curves for temperatures $160{ }^{\circ} \mathrm{C}, 170{ }^{\circ} \mathrm{C}$ and $180{ }^{\circ} \mathrm{C}$ were measured (Figure 1). This was done to better understand the sensitivity of the compound to temperature. For production of test samples from this rubber compound the highest temperature $180{ }^{\circ} \mathrm{C}$ was chosen. This temperature also corresponds to the vulcanization temperature selected in practice. Table 2 shows important vulcanization parameters subtracted from the vulcanization curve. Optimum of cure at this temperature is approximately 2.4 minutes.

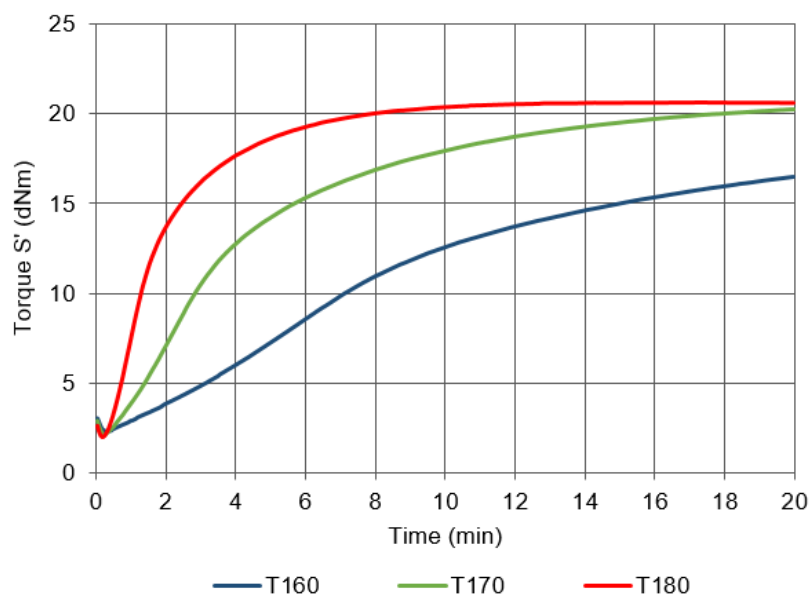

Figure 1. Curing curves of rubber compounds

Table 2. Curing specification for $180^{\circ} \mathrm{C}$.

\begin{tabular}{|c|c|}
\hline Max. torque $\mathbf{S}$ & $19.26 \mathrm{dN} . \mathrm{m}$ \\
\hline Scorch time $\left(\mathbf{t}_{\mathbf{s}}\right)$ & $0.51 \mathrm{~min}$ \\
\hline
\end{tabular}

\begin{tabular}{|l|l|}
\hline $\mathbf{1 0} \%$ cure $\left(\mathbf{t}_{\mathbf{1 0}}\right)$ & $0.62 \mathrm{~min}$ \\
\hline $\mathbf{5 0} \%$ cure $\left(\mathbf{t}_{\mathbf{5 0}}\right)$ & $1.42 \mathrm{~min}$ \\
\hline $\mathbf{9 0} \%$ cure $\left(\mathbf{t}_{\mathbf{9 0}}\right)$ & $4.96 \mathrm{~min}$ \\
\hline
\end{tabular}

\subsection{Preparation of test samples}

For this research, the mechanical tension test according to the standard ISO 37 was chosen. The standard also prescribes the shapes and dimensions of testing samples. To perform this test, the testing sample dumbbell - type 1 (Figure 2a) has been selected. Another test confirming the mechanical properties is the test determining tear strength according to the standard ISO 34-1. To perform this test, the samples crescent, graves and trousers were chosen (Figure 2b, c, d).

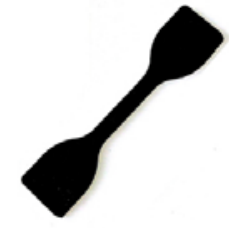

a)

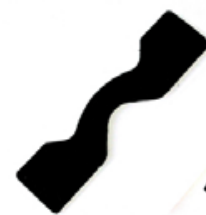

c)

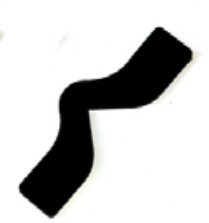

b)

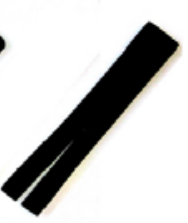

d)
Figure 2. Test samples: a) dumbbell (type 1); b) crescent; b) graves; d) trouser.

To carry out the experiment, it was necessary to design and produce an injection mold for all types testing samples. The designed mold includes a universal frame, into which mold plates for given shapes of samples are inserted as necessary. In case of compression molding, it was first necessary to remold the rubber compound with the assistance of a roll mill and to prepare the required thickness. Next the raw products were cut out in shape of the sheet. Then the raw products were inserted into the pre-heated molding machine and the sheets with dimensions 120 x $120 \mathrm{~mm}, 2 \mathrm{~mm}$ thick, were compression molding. Finally the testing rubber samples were cut out with the assistance of a shape knife, in the line of the material orientation to prevent mistaking the anisotropy direction. In case of injection molding the preplasticated compound was cut into belts for fill in the injection molding machine. Then the injection molding itself was performed. After injection molding the runner system was removed. The samples were produced from one charge of rubber compound. All groups of samples were made in comparable process conditions (Table 3 ).

Table 3. Process conditions of production.

\begin{tabular}{|c|c|c|c|}
\hline & $\begin{array}{c}\text { Compression } \\
\text { molding }\end{array}$ & $\begin{array}{c}\text { Injection } \\
\text { molding }\end{array}$ \\
\hline
\end{tabular}




\begin{tabular}{|c|c|c|c|}
\hline \multirow{2}{*}{ Temperature } & Mold & \multicolumn{2}{|c|}{$180^{\circ} \mathrm{C}$} \\
\cline { 2 - 4 } & $\begin{array}{c}\text { Rubber } \\
\text { compound }\end{array}$ & $23{ }^{\circ} \mathrm{C}$ & $100{ }^{\circ} \mathrm{C}$ \\
\hline Pressure & $\begin{array}{c}\text { Closing/ } \\
\text { Injection }\end{array}$ & $20 \mathrm{MPa}$ & $20 \mathrm{MPa}$ \\
\hline \multicolumn{2}{|c|}{ Curing time } & \multicolumn{2}{|c|}{$3 ; 4 ; 5 ; 6 \mathrm{~min}$} \\
\hline
\end{tabular}

\subsection{Physical tests}

After producing of the testing samples a test was carried out to determine the tensile stress-strain properties and also the test to determine the tear strength. In both cases the testing samples were clamped into jaws at both ends in the tensile stress machine Tensometer 2000 by Alpha Technologies. Test sample dumbbell was stretched by the prescribed constant speed $500 \mathrm{~mm} / \mathrm{min}$ until they were torn. In case of test sample crescent, graves and trouser, stretching speed was $100 \mathrm{~mm} / \mathrm{min}$. As for both groups of compression molded and injection molded testing samples, 4 series of measurement with different curing time (3 up to 6 minutes) were carried out, with the repeatability of ten samples to one series of measurement.

\section{Results}

The data recorded during the tensile strength test (Figure 3) showed that with the growing curing time the tension necessary to tear the testing sample grows. The given results demonstrate that the samples produced by injection molding demonstrate higher strength compared to the samples produced in the standard method, but within the optimum curing time $(5$ minutes $)$ this difference only amounts to $5.9 \%$.

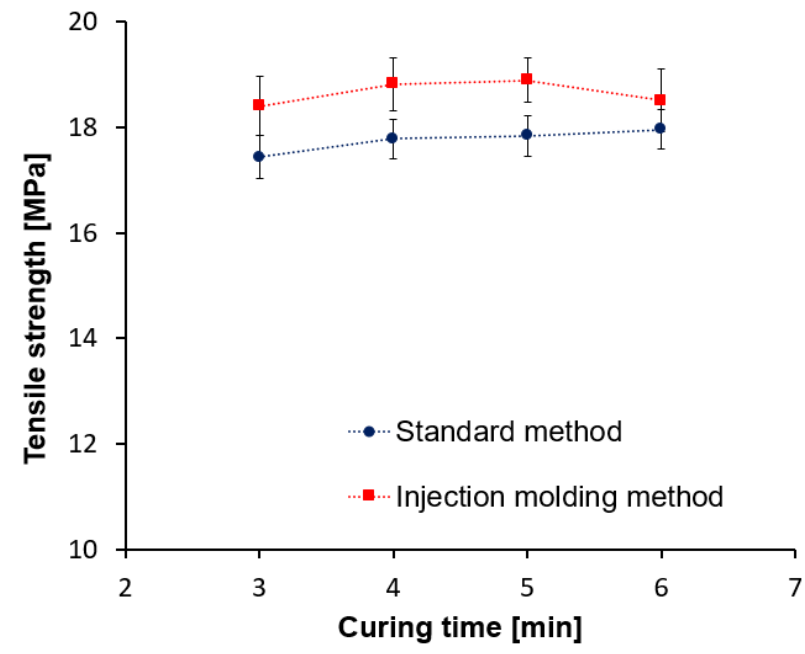

Figure 3. Tensile strength vs. curing time.

Another acquired result (Figure 4) demonstrates the dependence of the intrinsic strength of the graves sample. It is obvious that the intrinsic strength measured on this sample does not change significantly with the curing time. However, there are significant differences between the individual methods of producing the samples. The injection molded samples demonstrate $45.5 \%$ lower intrinsic strength than samples produced by the standard method. The results of the structural test of crescent sample (Figure 5) imply that, in case of all the manufacturing methods, with the growing curing time the intrinsic strength also grows. The samples produced by injection molding demonstrate the highest intrinsic strength. At the approximate optimum curing time of 5 minutes the injection molded crescent samples have $14.8 \%$ higher intrinsic strength than samples produced by the standard method.

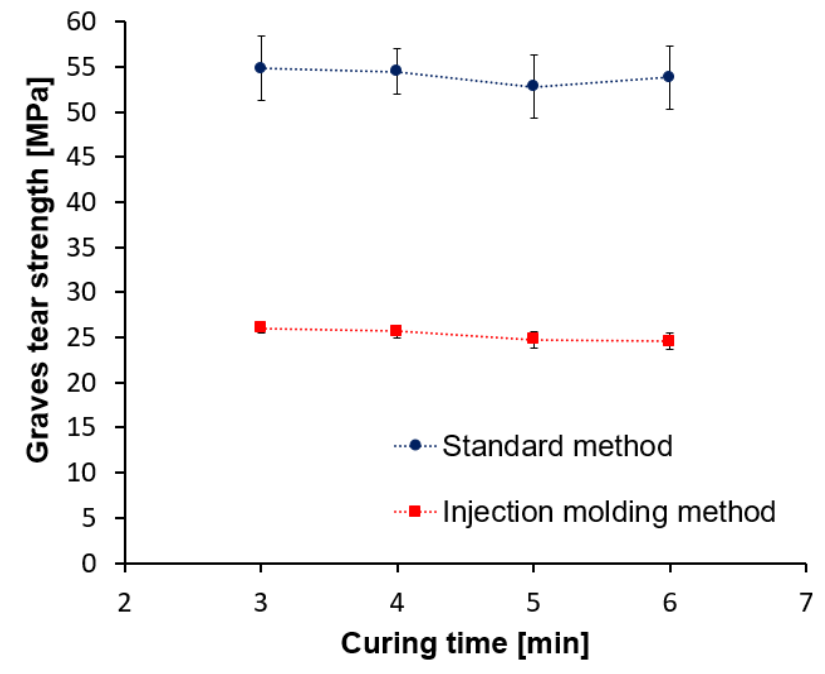

Figure 4. Graves tear strength vs. curing time.

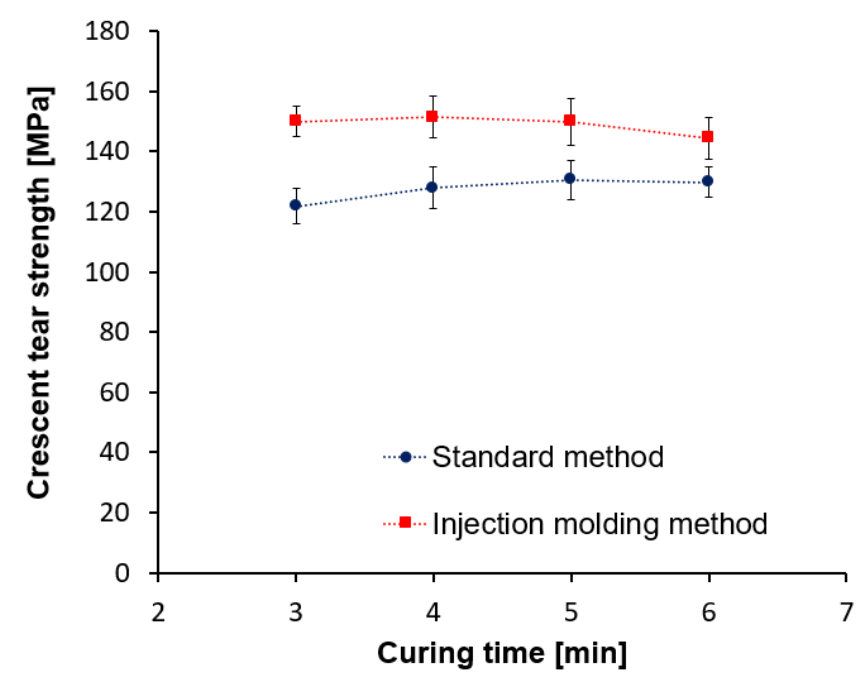

Figure 5. Crescent tear strength vs. curing time 


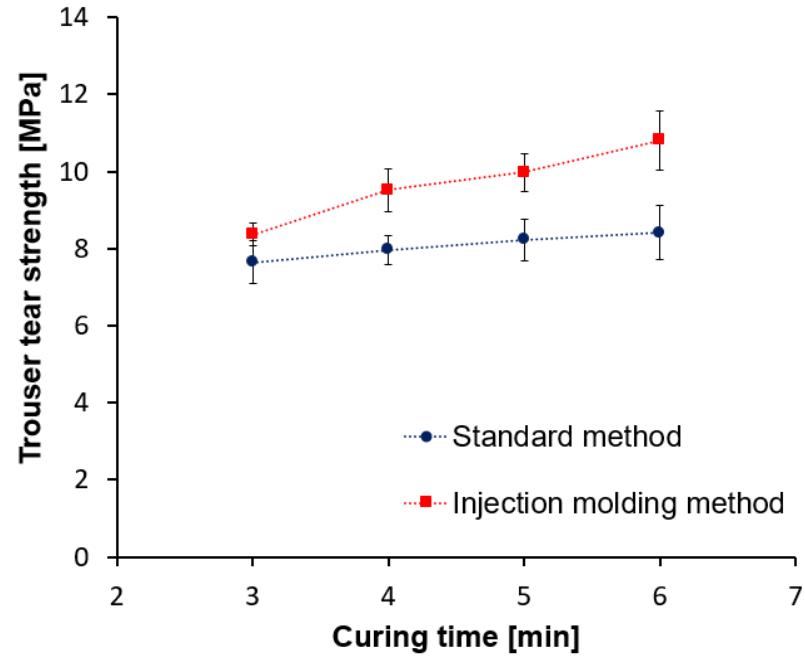

Figure 6. Trouser tear strength vs. curing time.

The last result of the structural test is the behavior of the intrinsic strength in case of the trouser sample (Figure 6). The results imply that with the growing curing time the intrinsic strength grows slightly, mainly in case of injection molded samples. From the point of view of the impact of the manufacturing process, the injection molded trouser samples at 5 minutes demonstrate up to $21.3 \%$ higher tear strength than samples produced in the standard method.

\section{Discussion}

The obtained results of tests performed on the produced testing samples showed certain differences in mechanical properties. To provide clearer evaluation there is a table (Table 4) which shows the increase $(+)$ or decrease $(-)$ in percentage of the measured properties of injected samples with respect to the samples produced by the standard method. The table evaluates the quantities measured in the time close to the optimum cure (5 minutes).

Table 4. The relative increase (decrease) in the measured properties of injection molded samples.

\begin{tabular}{|c|c|}
\hline $\begin{array}{c}\text { Measurement } \\
\text { property }\end{array}$ & $\begin{array}{c}\text { Injection } \\
\text { molding }\end{array}$ \\
\hline Tensile strength & $+5.9 \%$ \\
\hline Graves tear strength & $-45.5 \%$ \\
\hline Crescent tear strength & $+14.8 \%$ \\
\hline Trouser tear strength & $+21.3 \%$ \\
\hline
\end{tabular}

The injection molded samples have higher tensile strength and modulus of elasticity at the optimum curing time. This is caused by the higher degree of crosslinking. Owing to preheating of the compound in the plastication unit of an injection machine the crosslinking degree of the injection molded samples is higher at the same curing time than in case of samples produced in the standard method, i.e. compression molding. The injection molded samples with a cut placed perpendicularly to the loading direction (graves) demonstrate $45.5 \%$ lower intrinsic strength than samples produced in the standard method. To the contrary, the samples with a cut in the direction of loading (trouser) have intrinsic strength $21.3 \%$ higher than samples produced in the standard method. Such significant differences of intrinsic strength in case of individual samples are probably caused by different loading of the compound into the loading well in the course of manufacturing. In case of injection molding the well is loaded with the compound gradually on one side and thus the sample becomes anisotropic in the line of loading. In case of compression molding the compound is not rearranged so much and the orientation of the macromolecules in the sample structure is mainly given by the direction of rolling. When testing the graves sample it was possible to observe different cavity working. In case of injection molded samples the crack spread approximately at the $20^{\circ}$ angle to the direction of the acting tensile strength, while in case of compression molded samples the crack spread perpendicularly to the direction of the acting tensile strength.

\section{Conclusion}

The results of the performed tests showed that the standard preparation method used in case of testing samples (cutting out of the compression molded plate) can be applied also on compounds appointed to the production of injected products. However, the properties of samples produced by this method are not wholly objective, mainly in case of tear strength. The stated results of this research open new possibilities of the testing samples preparation in rubber-making industry, mainly in companies where the injection molding technology is used. It was determined that the preparation method of injection molded samples is viable and for testing of rubber compounds, or products made of such compounds, is more evident than in case of samples prepared by the standard method used up to the present time. In view of the results of this research, when producing injection molded rubber products, it is also recommended to use injection molded testing samples to test their tear properties. The problem of tear strength is to be studied further and to find new evidence that would confirm the theory of the different internal macromolecules arrangement due to injection. At present, cooperation with industrial practice has been established, which has also shown interest in the results and knowledge gained from this research. Future research will be extended to further rubber compounds for injection molding. Further physical properties will be investigated - Shore hardness and resilience. A structural test will be added for better understanding of the internal arrangement of rubber compounds.

\section{Acknowledgment}


This work was supported by the European Regional Development Fund under the project CEBIA-Tech Instrumentation No. CZ.1.05/2.1.00/19.0376 and by the Ministry of Education, Youth and Sports of the Czech Republic within the National Sustainability Program project no. LO1303 (MSMT-7778/2014). Moreover, it was supported by the Internal Grant Agency of TBU in Zlin: no. IGA/FT/2018/012.

\section{References}

1. Sezna J. A., 207(4), 12-19 (1993)

2. A. Arrillaga, A. M. Zaldua, A. S. Farid, A. S., J. Appl. Pol. Sci., 123(3), 1437-1454. (2012)

3. Broadbent, S. Rubber World, 257(3), 24-27. (2017)

4. Kyas, K., Staněk, M., Maňas, M., Maňas, D., Křumal, M., \& Holík, Z. Chemicke Listy, 105(15), 354-356. (2011).

5. Rubber Injection Moulding: A Practical Guide by J.A. Lindsay (2012) 